\title{
Effectiveness of Genetic Parameter Estimation in a Small Flock of Merino Sheep with Shallow Pedigree
}

\author{
Serdar Duru',a,*, Mehmet Koyuncu ${ }^{1, b}$ \\ ${ }^{l}$ Department of Animal Science, Faculty of Agriculture, Bursa Uludağ University, 16059 Bursa, Turkey
}

${ }^{*}$ Corresponding author

\begin{tabular}{l|l}
\hline A R T I C LE I N F O & A B S T R A C T \\
\hline & In this study, the genetic and non-genetic parameters were estimated for growth traits of Karacabey
\end{tabular}

Research Article merino sheep. Growth performance data refer to 1863 lambs born between 2016 and 2018. Analyses were carried out by restricted maximum likelihood fitting animal models and disregarding or including maternal genetic or maternal permanent environmental effect. Six different animal model

Received : 14/11/2019

Accepted : 16/12/2019 were fitted for all traits, and the most suitable model for each trait was chosen after Akaike information criterion test (AIC). Year of birth, age of dam, type of birth and lamb sex were significant sources of variation on birth weight (BW), average daily gain (ADG), Kleiber ratio (KR), weaning weight $(\mathrm{WW})$ and six month weight $(6 \mathrm{MW})$. Direct heritability $\left(h^{2}\right)$ for BW, ADG and $6 \mathrm{MW}$ were $0.12,0.02$ and 0.04 , respectively, however, for KR and WW were 0.00 model 6 (which

Keywords: Karacabey merino Growth traits Genetic parameter MTDFREML Sheep breeding the best). The estimates of maternal heritability $\left(\mathrm{m}^{2}\right)$ for ADG, KR and WW were $0.12,0.04$ and 0.04 , respectively in model 5, also maternal heritability were low for BW and $6 \mathrm{MW}$. Maternal permanent environmental effects $\left(c^{2}\right)$ have high contribution to the explanation growth traits and were estimated between 0.19 and 0.75 for these traits. These results showed that selecting for improved maternal and/or direct effects for Karacabey merino in the herd would generate very slow genetic improvement in growth traits.

\section{Introduction}

Although the contribution of sheep breeding to animal production is lower than that of cattle breeding in Turkey, it is an essential production area especially in rural areas because of being a source of income and employment for breeders. The studies on merino sheep in Turkey started in the first half of the 19th century and, later on at different times, progression and decline were showed. Merino sheep breeding was started in a planned way in the 1930's. Both new types of sheep yielding quality fleece wool were developed in crossbreeding studies and the studies were continued to reach desired levels of meat and milk production. One of the results of these studies is the Karacabey merino obtained as a result of crossbreeding of German mutton merino and Kivircik sheep.

Development of effective and optimum genetic evaluation and breeding programs for economically important growth traits in sheep breeding requires knowing of genetic parameters (Safari et al., 2005). Growth traits are affected by direct additive genetic effects and maternal effects (De Albuquerque and Meyer, 2001). When these effects are important and not taken into account, genetic parameters are biasedly overestimated and this reduces selection effectiveness (Dodenhoff et al., 1999; Maniatis and Pollott, 2002). In order to achieve optimum genetic improvement especially in growth traits both direct and maternal components should be taken into account. Moreover, if there is an antagonistic relationship between direct and maternal effects, this is more important (Meyer, 1992). Birth weight of an animal and especially early growth rate until weaning time is determined by not only its genetic potential but also maternal environment (Mandal et al., 2006). Mother contributes to progeny 
performance in two ways. The first of these is direct genetic effect and the second is the ability to provide a good environment. The mother's ability of providing an appropriate environment for its offspring is genetic and environment originated. The environmental one is subdivided into two, namely permanent and temporary environments. Maternal additive genetic component passes down to the progeny, but it may show itself only when the female progeny has her own offspring. Maternal effects reflect mainly the mother's milk production and mothering ability in intra-uterus conditions. These maternal effects have three reasons (Falconer and Mackay, 1996).

- Those which take place because of the mother's own genotype for milking and mothering ability (maternal additive effects),

- those which are permanent among all lambs of a mother' but not additive genetic originated (permanent environmental effects),

- those which are individually related to lambs (temporary environmental effects).

A mother's genotype affects phenotype of the progeny through maternal effects affecting growth and an example of half of direct additive genes. Maternal effects in mammal species affect growth traits especially prior to weaning. Since an important amount of feed consumed prior to weaning is composed of milk especially in lambs, maternal effects are more important compared to cattle. The estimate of (co)variance components occurring as a result of maternal effects was simplified via REML algorithms which can be used for appropriate animal models (Meyer, 1997). Modern statistical methods used for the estimation of variance components allow for splitting genetic variance into direct and maternal variances. What's more, direct and maternal effects may take part in models used for genetic evaluations thanks to linear models (Mrode, 2014). However, differentiating direct and maternal effects meaningfully requires a sufficient data structure. To differentiate additive direct, additive maternal and permanent environmental maternal effects, it is necessary to have yield records belonging to sheep which have been recorded during a few lambing years.

In recent years, in many studies investigating the variation in growth traits in different sheep breeds, maternal effects were examined by using different models (Mandal et al., 2008; Rashidi et al., 2008; Di et al., 2011; Mohammadi et al., 2011; Abbasi et al., 2012; Tamioso et al., 2013; Zishiri et al., 2014; Khorsand et al., 2014; Shiotsuki et al., 2014; Gowane et al., 2015; Valerio et al., 2015). The purpose of this study is to estimate the variance components and genetic parameters for growth traits and Kleiber ratio of Karacabey merino sheep by using different models and determine the best model. Kleiber ratio is suggested as the indirect selection criterion for feed conversion activity in grazing land conditions (Scholtz and Roux, 1988).

\section{Materials and Methods}

\section{Data}

Data was provided from a private farm in the Bursa city of Turkey. In this study, the records belonging to 1863 lambs of 60 rams born from 1287 sheep between 20162018 were used (Table 1). The lambs were born in the spring and suckled their mother for 3 months. In these lambs, birth weight (BW), weaning weight (WW), average daily weight gain from birth to weaning time (ADG), six month weight (6MW) and Kleiber ratio (KR) between birth and weaning time were evaluated. Kleiber ratio was defined as ADG/WW ${ }^{0.75}$ (Kleiber, 1947).

\section{Data Analysis}

The data was analyzed via the variance analysis and in the GLM procedure (SPSS, 2008). As fixed effects, year of birth, age of dam, birth type and lamb sex were taken into account and all the effects were found significant $(\mathrm{P}<0.05)$.

The (co)variance components were estimated via the REML. In order to estimate the (co)variance components and genetic parameters, the MTDFREML and six different univariate animal models were used (Boldman et al., 1995). In these models, various combinations of maternal genetic and environment effects were used.

$$
\begin{array}{llr}
\mathrm{y}=\mathrm{Xb}+\mathrm{Za}+\mathrm{e} & (\text { Model 1) } \\
\mathrm{y}=\mathrm{Xb}+\mathrm{Za}+\mathrm{Wm}+\mathrm{e} & (\operatorname{Cov}(\mathrm{a}, \mathrm{m})=0) & (\text { Model 2) } \\
\mathrm{y}=\mathrm{Xb}+\mathrm{Za}+\mathrm{Wm}+\mathrm{e} & \left(\operatorname{Cov}(\mathrm{a}, \mathrm{m})=A \sigma_{\mathrm{am}}\right) & (\text { Model 3) } \\
\mathrm{y}=\mathrm{Xb}+\mathrm{Za}+\mathrm{Wm}+\mathrm{Sc}+\mathrm{e} & (\operatorname{Cov}(\mathrm{a}, \mathrm{m})=0) & (\text { Model 4) } \\
\mathrm{y}=\mathrm{Xb}+\mathrm{Za}+\mathrm{Wm}+\mathrm{Sc}+\mathrm{e} & \left(\operatorname{Cov}(\mathrm{a}, \mathrm{m})=A \sigma_{\mathrm{am}}\right) & (\text { Model 5) } \\
\mathrm{y}=\mathrm{Xb}+\mathrm{Za}+\mathrm{Sc}+\mathrm{e} & & (\text { Model 6) }
\end{array}
$$

In these models, $y$ is the observation values vector for each trait, $b$ indicates fixed effects (year, birth type, sex, age of dam) vector, a, m, c and e indicate direct additive genetic effects (animal), maternal additive genetic effects, maternal permanent environment effects and the error, respectively. $X, Z, W$ and $S$ are the design, incidence matrices belonging to these effects. $A$ is the numerator relationship matrix. The assumptions used in the analysis are as follows:

$$
\begin{aligned}
& \mathrm{V}(\mathrm{a})=A \sigma_{a}^{2}, \\
& \mathrm{~V}(\mathrm{~m})=A \sigma_{m}^{2}, \\
& \mathrm{~V}(\mathrm{c})=I_{d} \sigma_{c}^{2}, \\
& \operatorname{Cov}(\mathrm{a}, \mathrm{m})=A \sigma_{a m}, \\
& \mathrm{~V}(\mathrm{e})=I_{n} \sigma_{e}^{2}
\end{aligned}
$$

where; $I_{d}$ and $I_{n}$ are the identity matrices with orders equal to number of dam and animals, $\sigma_{a}^{2}, \sigma_{m}^{2}, \sigma_{c}^{2}, \sigma_{a m}$ and $\sigma_{e}^{2}$ are the direct additive genetic variance, maternal additive genetic variance, maternal permanent environment variance, covariance between additive direct and maternal effects and environmental variance, respectively. These variance components are divided into phenotypic variance, and so heritability $\left(h^{2}\right)$, maternal heritability $\left(\mathrm{m}^{2}\right)$, common environmental effects $\left(c^{2}\right)$ were calculated. Moreover, the repeatability for the total maternal effect or sheep performance, $t_{m}=h^{2} /$ $4+m^{2}+c^{2}+h$. m. $r_{a m}$ formula was used. And also the total heritability was calculated via $h_{T}^{2}=\left(\sigma_{a}^{2}+0.5 \sigma_{m}^{2}+1.5 \sigma_{a m}\right) / \sigma_{P}^{2}$ (Willham, 1972). Since this equality is $\sigma_{a m}=r_{a m} \cdot \sigma_{a} \cdot \sigma_{m}$, it can also be expressed like this: $h_{T}^{2}=h^{2}+0.5 m^{2}+1.5$ h.m.r $r_{a m}$. 
If the value of $-2 \log$ likelihood variance is below $10^{-9}$ in the Simplex function, it is accepted that convergence was achieved. In order to determine the best model for each trait the Akaike's Information Criterion (AIC) was used (Akaike, 1974).

$$
\mathrm{AIC}=-2 \log L+2 p
$$

Where $\log L$ is the maximized Log likelihood and $p$ is the number of parameters for each model. The model taking the lowest AIC value was accepted as the most appropriate model. Additionally, the differences between the models with AIC values which are closest to the one found in this model were compared via using the likelihood ratio test (LRT). For LRT, the difference between $-2 \log L$ values was evaluated by using the Chi-square test.

Table 1. The characteristics of the data structure for growth traits in Karacabey merino

\begin{tabular}{l|rrrrr}
\hline \multicolumn{1}{c|}{ Item } & BW & ADG & KR & WW & 6MW \\
\hline Number of lamb & 1863 & 1713 & 1713 & 1713 & 1089 \\
Number of sire & 60 & 60 & 60 & 60 & 60 \\
Number of dam & 1287 & 1218 & 1218 & 1218 & 855 \\
Mean, kg & 4.69 & 297.09 & 25.40 & 26.80 & 46.24 \\
Standard error of mean & 0.03 & 2.94 & 0.19 & 0.25 & 0.34 \\
Standard deviation & 0.87 & 70.17 & 4.75 & 5.98 & 6.44 \\
\hline Coefficient of variation CV (\%) & 18.49 & 23.62 & 18.68 & 22.33 & 13.92 \\
\hline
\end{tabular}

BW: Birth weight; WW: Weaning weight; 6MW: Six month weight; ADG: Average daily weight gain from birth to weaning, gr; KR: Kleiber ratio between birth and weaning.

Table 2. Akaike's Information Criterion Values Calculated form Different Models for Growth Traits of Karacabey Merino Sheep

\begin{tabular}{l|ccccc}
\hline \multirow{2}{*}{ Model } & \multicolumn{5}{c}{ Traits } \\
\cline { 2 - 6 } & BW & ADG & KR & WW & 6 MW \\
\hline 1 & 215.01 & 5359.67 & 2307.56 & 2450.04 & 1664.53 \\
2 & 198.85 & 5358.08 & 2241.88 & 2442.91 & 1668.53 \\
3 & 199.22 & 5356.08 & 2239.44 & 2442.65 & 1666.43 \\
4 & 182.40 & 5353.61 & 2204.95 & 2429.60 & 1666.03 \\
5 & 184.33 & 5359.18 & 2206.67 & 2432.64 & 1667.74 \\
6 & 180.40 & 5351.66 & 2202.94 & 2428.64 & 1664.02 \\
\hline
\end{tabular}

BW: Birth weight; WW: Weaning weight; 6MW: Six month weight; ADG: Average daily weight gain from birth to weaning, gr; KR: Kleiber ratio from birth to weaning.

\section{Results and Discussion}

The ratios of the lambs born single, twin, triplet and quadruplet were $56.65 \%, 42.19 \%, 0.93 \%$ and $0.23 \%$, respectively. About $8 \%$ of the lambs died until weaning time. While the average number of offspring per mother was 1.44 at birth, this value decreased to 1.27 in the $6^{\text {th }}$ month. The AIC values calculated in all the models for each trait were given in Table 2. The most appropriate model is 6. This model not including maternal genetic effects covers direct genetic effects and maternal permanent environmental effects.

The LRT results between model 6 and the other models are seen in Table 3. As it was mentioned before, according to the employed Chi-square test, for all the traits, the difference between model 4-6 and model 5-6 is not significant. Additionally, for $6 \mathrm{MW}$, the difference between the other models and model 6 is not significant, either. However, for the other traits, the difference between model 6 and models 1,2 and 3 is significant $(\mathrm{P}<0.05)$.

The (co)variance components and genetic parameters for the growth traits and the Kleiber ratio were given in Table 4 . In model 6, the additive direct heritability $\left(h_{d}^{2}\right)$ for $\mathrm{BW}, \mathrm{ADG}, \mathrm{KR}, \mathrm{WW}$ and $6 \mathrm{MW}$ was found $0.12,0.00,0.00$, 0.02 and 0.04 , respectively. In model 5 , the same parameter was $0.02,0.08$ and 0.06 for $\mathrm{KR}, \mathrm{WW}$ and $6 \mathrm{MW}$, respectively. In the traits where the direct maternal genetic correlation is negative ( $\mathrm{KR}, \mathrm{WW}, 6 \mathrm{MW})$, the direct heritability was found higher than the total heritability.
The maternal genetic effects are not included in model 6. However, in model 4 and model 5 taking these effects into account, the maternal variance $\left(\sigma_{m}^{2}\right)$ and, hence the maternal heritability $\left(\mathrm{m}^{2}\right)$, was estimated either very small or zero. $\mathrm{m}^{2}$ was estimated 0.04 for KR and $\mathrm{WW}$, and 0.14 for ADG in model 5. For BW, WW and 6MW, the maternal permanent environmental effects $\left(c^{2}\right)$ were found as 0.53 , 0.44 and 0.19 , respectively; for ADG and KR, they were found as 0.75 and 0.44 , respectively. In this study, the $c^{2}$ estimates were greater than $\mathrm{m}^{2}$ ones. This may indicate that environment has great effect on mothers' milk yields. The direct-maternal genetic correlation $\left(r_{a m}\right)$ was found as either negative or positive limit values. For BW and ADG, it was found 0.99 and 1.00; for $\mathrm{KR}$ and $\mathrm{WW}$, it was found -0.99 and, for $6 \mathrm{MW}$, it was -1.00 (Table 4). Their standard errors are rather great. The repeatability of ewe performance $\left(t_{m}\right)$ were found as $0.56,0.45,0.20$ respectively for $\mathrm{BW}, \mathrm{WW}, 6 \mathrm{MW}$ in the best model; it was found as 0.28 and 0.75 respectively for ADG and KR, which was rather close to the other models. The total heritability $\left(h_{T}^{2}\right)$ for BW, WW, 6MW, ADG and KR, were estimated as $0.12,0.02,0.04,0.00$ and 0.00 respectively in model 6 in present study. In the other models where negative direct-maternal genetic correlation was obtained, $h_{T}^{2}$ was calculated lower than the direct heritability; for WW in model 5 , it decreased from 0.08 to 0.01 ; for $\mathrm{MW}$, it decreased from 0.06 to 0.02 . 
Table 3. The likelhood ratio test between the most appropriate model used in the estimation of the variance components for Growth Traits in Karacabey merino sheep and the other closest models

\begin{tabular}{l|ccccc}
\hline \multirow{2}{*}{ Trait } & \multicolumn{5}{|c}{ Differences between the -2LogL values of the models } \\
\cline { 2 - 6 } & $1-6$ & $2-6$ & $3-6$ & $4-6$ & $5-6$ \\
\hline BW & $36.61^{*}$ & $16.40^{*}$ & $18.82^{*}$ & 0.00 & 0.06 \\
ADG & $10.00^{*}$ & $4.41^{*}$ & $4.41^{*}$ & 0.05 & 3.52 \\
KR & $106.62^{*}$ & $36.95^{*}$ & $36.50^{*}$ & 0.02 & 0.26 \\
WW & $23.41^{*}$ & $12.27^{*}$ & $14.02^{*}$ & 1.03 & 0.00 \\
6MW & 2.50 & 2.50 & 2.41 & 0.00 & 0.28 \\
\hline
\end{tabular}

BW: Birth weight; WW: Weaning weight; 6MW: Six month weight; ADG: Average daily weight gain from birth to weaning, gr; KR: Kleiber ratio from birth to weaning. ${ }^{*} \chi^{2}(\mathrm{P}<0.05)$

Table 4. Estimates of variance components and genetic parameters for some traits in Karacabey merino sheep

\begin{tabular}{|c|c|c|c|c|c|c|c|}
\hline Traits & Models & $\sigma_{a}^{2}$ & $\sigma_{m}^{2}$ & $\sigma_{c}^{2}$ & $\sigma_{a m}$ & $\sigma_{e}^{2}$ & $\sigma_{P}^{2}$ \\
\hline \multirow{3}{*}{ BW } & 4 & 0.065 & 0.00001 & 0.279 & \multirow{3}{*}{0.007} & 0.187 & 0.531 \\
\hline & 5 & 0.062 & 0.0008 & 0.272 & & 0.189 & 0.531 \\
\hline & 6 & 0.065 & & 0.279 & & 0.187 & 0.531 \\
\hline \multirow{3}{*}{$\mathrm{ADG}$} & 4 & 0.006 & 83.40 & 1226.34 & \multirow{3}{*}{180.910} & 3391.980 & 4701.726 \\
\hline & 5 & 49.90 & 655.89 & 467.61 & & 3474.870 & 4829.180 \\
\hline & 6 & 0.003 & & 1315.89 & & 3386.790 & 4702.683 \\
\hline \multirow{3}{*}{$\mathrm{KR}$} & 4 & 0.00002 & 0.00001 & 16.740 & \multirow{3}{*}{-0.660} & 5.330 & 22.070 \\
\hline & 5 & 0.448 & 0.986 & 15.960 & & 5.180 & 21.914 \\
\hline & 6 & 0.00003 & & 16.550 & & 5.380 & 21.930 \\
\hline \multirow{3}{*}{ WW } & 4 & 0.645 & 0.0001 & 12.164 & \multirow{3}{*}{-1.600} & 14.670 & 27.479 \\
\hline & 5 & 2.143 & 1.195 & 11.861 & & 13.858 & 27.457 \\
\hline & 6 & 0.677 & & 12.069 & & 14.618 & 27.364 \\
\hline \multirow{6}{*}{$6 \mathrm{MW}$} & 1 & 3.249 & & & \multirow{4}{*}{-2.146} & 33.058 & 36.307 \\
\hline & 2 & 3.220 & 0.00069 & & & 33.065 & 36.286 \\
\hline & 3 & 3.630 & 1.269 & & & 33.590 & 36.343 \\
\hline & 4 & 1.288 & 0.0001 & 7.086 & & 27.890 & 36.264 \\
\hline & 5 & 2.182 & 0.46 & 6.994 & \multirow[t]{2}{*}{-1.003} & 27.680 & 36.313 \\
\hline & 6 & 1.324 & & 6.994 & & 27.990 & 36.308 \\
\hline Traits & Models & $h_{d}^{2} \pm S E$ & $m^{2} \pm S E$ & $c^{2}$ & $r_{a m} \pm S E$ & $t_{m}$ & $h_{T}^{2}$ \\
\hline \multirow{3}{*}{ BW } & 4 & $0.12 \pm 0.10$ & $0.00 \pm 0.09$ & $0.53 \pm 0.11$ & \multirow{3}{*}{$0.99 \pm 1.21$} & 0.56 & 0.12 \\
\hline & 5 & $0.12 \pm 0.10$ & $0.00 \pm 0.13$ & $0.51 \pm 0.11$ & & 0.56 & 0.14 \\
\hline & 6 & $0.12 \pm 0.09$ & & $0.53 \pm 0.06$ & & 0.56 & 0.12 \\
\hline \multirow{3}{*}{$\mathrm{ADG}$} & 4 & $0.00 \pm 0.05$ & $0.02 \pm 0.08$ & $0.26 \pm 0.11$ & \multirow{3}{*}{$1.00 \pm 1.65$} & 0.28 & 0.01 \\
\hline & 5 & $0.01 \pm 0.07$ & $0.14 \pm 0.15$ & $0.09 \pm 0.14$ & & 0.27 & 0.13 \\
\hline & 6 & $0.00 \pm 0.05$ & & $0.28 \pm 0.08$ & & 0.28 & 0.00 \\
\hline \multirow{3}{*}{ KR } & 4 & $0.00 \pm 0.03$ & $0.00 \pm 0.09$ & $0.76 \pm 0.09$ & \multirow{3}{*}{$-0.99 \pm 1.03$} & 0.76 & 0.00 \\
\hline & 5 & $0.02 \pm 0.06$ & $0.04 \pm 0.12$ & $0.73 \pm 0.10$ & & 0.75 & 0.00 \\
\hline & 6 & $0.00 \pm 0.05$ & & $0.75 \pm 0.04$ & & 0.75 & 0.00 \\
\hline \multirow{3}{*}{ WW } & 4 & $0.02 \pm 0.06$ & $0.00 \pm 0.11$ & $0.44 \pm 0.13$ & \multirow{3}{*}{$-0.99 \pm 1.21$} & 0.48 & 0.02 \\
\hline & 5 & $0.08 \pm 0.08$ & $0.04 \pm 0.15$ & $0.43 \pm 0.13$ & & 0.41 & 0.01 \\
\hline & 6 & $0.02 \pm 0.05$ & & $0.44 \pm 0.69$ & & 0.45 & 0.02 \\
\hline \multirow{6}{*}{$6 \mathrm{MW}$} & 1 & $0.09+0.094$ & & & \multirow{4}{*}{$-0.99 \pm 1.14$} & 0.02 & 0.09 \\
\hline & 2 & $0.09+0.10$ & $0.00002 \pm 0.099$ & & & 0.02 & 0.09 \\
\hline & 3 & $0.10+0.107$ & $0.0349 \pm 0.198$ & & & 0.00 & 0.03 \\
\hline & 4 & $0.04 \pm 0.08$ & $0.00 \pm 0.14$ & $0.20 \pm 0.17$ & & 0.20 & 0.04 \\
\hline & 5 & $0.06 \pm 0.09$ & $0.01 \pm 0.21$ & $0.19 \pm 0.17$ & \multirow[t]{2}{*}{$-1.00 \pm 1.83$} & 0.19 & 0.02 \\
\hline & 6 & $0.04 \pm 0.07$ & & $0.19 \pm 0.11$ & & 0.20 & 0.04 \\
\hline
\end{tabular}

BW: Birth weight; WW: Weaning weight; 6MW: Six month weight; ADG: Average daily weight gain from birth to weaning, gr; KR: Kleiber ratio from birth to weaning, Phenotypic variance $\left(\sigma_{P}^{2}\right)$, residual variance $\left(\sigma_{e}^{2}\right)$, direct additive genetic variance $\left(\sigma_{a}^{2}\right)$, maternal additive genetic variance $\left(\sigma_{m}^{2}\right)$, maternal permanent environmental (common) variance $\left(\sigma_{c}^{2}\right)$, covariances between direct and maternal additive genetic effects $\left(\sigma_{a m}\right)$, direct heritabilities $\left(h_{d}^{2}\right)$, maternal heritabilities $\left(\mathrm{m}^{2}\right)$, the ratio of maternal permanent environmental variance to phenotypic variance $\left(c^{2}\right)$, correlation between direct and maternal additive genetic effects $\left(r_{a m}\right)$, repeatability of ewe performance $\left(t_{m}\right)$, total heritability $\left(h_{T}^{2}\right)$, Standart error (SE), *Some values are shown so that it appears more number after the decimal point. 
In various sheep breeds, for the body weights, it was reported that the direct heritability decreased from 0.07 to 0.29 at birth, from 0.07 to 0.40 at weaning and from 0.06 to 0.50 in the 6th month (Kushwaha et al., 2009; Jafaroghli et al., 2010; Di et al., 2011; Zishiri et al., 2014; Gowane et al., 2015). For the Kleiber ratio, it was found to vary between 0.03 and 0.08 (Rashidi et al., 2008; Mokhtari et al., 2013) and 0.05 (Mohammadi et al., 2011, 2013). For this breed, $h_{d}^{2}$ was reported previously as $0.08,0.12$ and 0.11 for BW, WW and ADG respectively (Ozcan et al., 2005). The $h_{d}^{2}$ values found in present study were much smaller than the ones obtained from previous studies. However, while the value found for BW (0.12) was close to those which some researchers reported (Di et al., 2011; Abbasi et al., 2012; Mohammadi et al., 2013), it was higher than others (Ozcan et al., 2005; Jafaroghli et al., 2010; JalilSarghale et al., 2014).

Although maternal effects decrease with age in mammals, they are important in young animals. However, the results of this study indicate that maternal genetic effects have a limited effect on the growth of lambs. In some studies, $m^{2}$ was found higher compared to present study (for BW, it was found as $0.14,0.18,0.20,0.23$; for WW and 6MW, it was found as 0.15 and 0.21) (Jafaroghli et al., 2010; Di et al., 2011; Mokhtari et al., 2013; Gowane et al., 2015). On the other hand, in this study, the values found for KR and ADG were close to those which Rashidi et al. (2008) (for BW, it was 0.03) and Gowane et al., (2015) (for ADG, it was 0.16) reported. The $m^{2}$ values in the literature found in the same breed were 0.09, 0.04 and 0.04 for BW, WW, ADG, respectively. Although $c^{2}$ was found higher than the values in the literature, these results indicated that these effects decreased with increasing age, which is in line with the literature. In other words, $c^{2}$ affect early life period traits more. $c^{2}$ affect birth weight especially at the end of pregnancy through nutritional level and uterus capacity. However, it can be stated that mother's milk yield and mothering behavior are more important at weaning. It was previously reported that in the same breed $c^{2}$ was $0.19,0.08$ and 0.09 for BW, WW and ADG and it was stated to be an impotant source of variance for BW (Ozcan et al., 2005). The $c^{2}$ calculated in present study was bigger than the previously reported for BW in other breeds $(0.09,0.11,0.12,0.19,0.27)$, but it was smaller than those which were reported for other traits (Kushwaha et al., 2009; Di et al., 2011; Abbasi et al., 2012; Zishiri et al., 2014; Gowane et al., 2015).

The results of the present study indicate that it will probably be difficult to become successful in the selection to be made for growth traits in Karacabey merino sheep in this herd. Maternal effects are very important especially for early growth traits. In animal models, accounting for genetic parameters for the traits affected by maternal effects depends both on the model used in the analysis and the structure of the model. In some studies, the genetic correlation between direct and maternal effects was found positive at different levels. The highest correlations were 0.44, 0.23, 1.00 for BW, WW and 6MW (Abbasi et al., 2012), 0.23 for BW (Jafaroghli et al., 2010), and 0.13 and 0.12 for BW and ADG (Rashidi et al., 2008). This indicates that the selection can be made in the same direction for the traits under discussion. In sheep breeding, in most production system, sheep and lambs are kept together and thus the interaction between mother and newborn lambs may be one of the most important factors affecting lamb production. This interaction seen in sheep is more attention-grabbing in other farm animals such as pigs and cattle. This effect partly reflects direct-maternal genetic correlation (Abbasi et al., 2012). In different sheep breeds, negative correlations were found between additive direct and additive maternal effects on growth traits $(-0.50,-0.89$, -0.89 and -0.91 for BW, WW, 6MW and ADG (Gowane et al., 2015), -0.91 and -0.98 for BW and WW (Zishiri et al., 2014)). In the same breed, in another study, $-0.63,-0.92$ and -0.90 were reported for BW, WW, ADG (Ozcan et al., 2005). These estimates are high as well as biologically reasonable. However, negative $r_{a m}$ is seen frequently and this is considered as a statistical rather a biological subject in animal improvement (Meyer, 1997; Eler et al., 2000). The negative $r_{a m}$ values may indicate the antagonism between the effects of genes related with growth and mothering ability. The antagonism between these effects may result either from the antagonism between an individual's growth genes and maternal contribution or a natural selection at a moderate level (Tosh and Kemp, 1994). According to Roff (2002), antagonistic pleiotropy has long been considered as a mechanism to allow for seeing the genetic variance. For this reason, selection for direct additive genetic effects, may reduce mothering ability; for pre weaning traits, it makes it difficult to make selection together (Gowane et al., 2015). Researchers reported different reasons for these results. Firstly, it was reported that maternal effects approached the limit probably due to insufficient amount of data. Moreover, another possible reason was the mistake of including some important constant effects in the model (Robinson, 1996). Another reason also might have been the presence of a higher variation between sires and dams or a bigger genetic variance or surprisingly environmental effects (Vergara et al., 2009).

It was reported that it was practically difficult of partition of $\mathrm{m}^{2}$ and $c^{2}$ and, for this reason, high and negative $r_{a m}$ was obtained (Maniatis and Pollott, 2002; Mandal et al., 2006; Heydarpour et al., 2008). This difficulty in partition of $m^{2}$ and $c^{2}$ can also be explained by insufficient years-long genetic relationship, incidental admission to herds and unplanned separation. What's more, it is expressed that the ability of partition of $\mathrm{m}^{2}$ and $c^{2}$ depends on where there is a family structure between mothers and the number of fathers resulting from these mothers (Zishiri et al., 2014). In present study, although the repeatability of ewe performance calculated for BW was bigger than some values given in the literature $(0.16,0.26$, 0.26) (Kushwaha et al., 2009; Mohammadi et al., 2011; Mokhtari et al., 2013; Gowane et al., 2015), it is in line with the value of 0.56 found by Assan et al. (2002) for Sabi sheep and the values of $0.46-0.54$ calculated by Tosh and Kemp (1994) for various breeds. The values of $0.07,0.13$ and 0.26 reported for WW and those of $0.05,0.10,0.12$ for 6MW (Kushwaha et al., 2009; Mokhtari et al., 2013; Gowane et al., 2015) are lower than the results of this study. For $t_{m}$ KR, 0.012 was found by Mohammadi et al. (2011). These values include total maternal effect and additive transmitting ability. The $t_{m}$ estimates do not only reflect the total repeatability of ewe performance level, but they can also be determined proportionally more precisely in both bigger set of data and the model becomes relatively stronger as long as there are maternal effects in the model. 
On the other hand, separation of the total ewe performance into its components $\left(h^{2}, m^{2}, c^{2}\right.$ and $\left.r_{a m}\right)$ is more difficult because of the need for mothers' more frequently repeated records. $t_{m}$ estimates a sheep's future performance and can be used in the identification and culling of sheep with lower value and is sufficient for estimating phenotypical progress to be achieved through culling. However, in order to estimate the genetic progress to be obtained through selection requires reliable estimates of $h^{2}, m^{2}$ and $r_{a m}$. Moreover, in order to develop maternal performance, additive and non-additive maternal effects need to be partitioned correctly. Although the present data in the study meet these criteria partly, it may be stated that the estimate of partition of $m^{2}$ and $c^{2}$ and $r_{a m}$ cannot be fully met.

The results for $h_{T}^{2}$ in the study are usually lower than the values reported in the literature. $0.21,0.15,0.17,0.15$ were reported for $\mathrm{BW}, \mathrm{WW}, 6 \mathrm{MW}, \mathrm{ADG}$, respectively (Gowane et al., 2015); 0.25, 0.18, 0.16 were reported for BW, WW, 6MW (Kushwaha et al., 2009); 0.05 was reported for KR (Mohammadi et al., 2011). On the contrary, they are similar to our findings of 0.15 and 0.16 reported by Jalil-Sarghale et al. (2014) and Jafaroghli et al. (2010) for BW (0.12 in model 6; 0.14 in model 5). When the maternal effects are important, the total heritability become important in animal breeding (Abegaz et al., 2005). In present study also the total heritability is usually very low. The inability of precisely partition of $m^{2}$ and $c^{2}$ is an important factor in this matter.

\section{Conclusion}

In conclusion, low genetic variation was found for most of traits in this study. In this herd, the total heritability for some traits varied between 0.00 and 0.12 . These results indicate that an important genetic progress cannot be achieved through direct or mass selection to be made according to phenotypes. However, in this set of data, it is likely to observe very little genetic progress for birth weight. Non-genetic effects made up an important part of phenotypical variance for all traits. Although these effects decreased until later times after birth, they continued. In this herd, these environmental factors, especially feeding practices, should be developed. For this reason, disregarding non-genetic factors may lead to biases in genetic parameter estimation. Although it was not given in Table 4, in model 1 including only the direct additive effects, the direct and total heritability was estimated extremely big. However, in models 2 and 3 excluding the maternal permanent environmental effects, the maternal heritability was estimated extremely big. For some traits, the direct additive-maternal covariance was estimated negative and very big. This has an important negative effect on the estimation of the total genetic progress to be achieved through selection. In order to increase the genetic variance in this herd, such practices as taking all the males to breeding from outside can be made. Then, it can be expected that using further pedigree and yield records and making breeding value estimates using more sophisticated methods based on BLUP and, besides this, taking both direct and maternal effects into consideration will increase progress to be achieved through selection.

\section{References}

Abbasi MA, Abdollahi-Arpanahi R, Maghsoudi A, Torshizi RV, Nejati-Javaremi A. 2012. Evaluation of models for estimation of genetic parameters and maternal effects for early growth traits of Iranian Baluchi sheep. Small. Rumin. Res., 104: 6269.

Abegaz S, Van Wyk JB, Olivier JJ. 2005. Model comparisons and genetic and environmental parameter estimates of growth and the Kleiber ratio in Horro sheep. S. Afr. J. Anim. Sci., 35: 3040.

Akaike H. 1974. A new look at the statistical model identification. IEEE T. Automat. Contr., 19: 716-723.

Assan N, Makuza S, Mhlanga F, Mabuku O. 2002. Genetic evaluation and selection response of birth weight and weaning weight in Indigenous Sabi sheep. Asian-Australas. J. Anim. Sci., 15: 1690-1694.

Boldman KG, Kriese LA, Van Vleck LD, Van Tassel CP, Kachman, SD. 1995. A manual for use of MTDFREML. A set of programs to obtain estimates of variances and covariances [DRAFT]. Washington, DC: U.S. Department of Agriculture, Agricultural Research Service.

De Albuquerque LG, Meyer K. 2001. Estimates of direct and maternal genetic effects for weights from birth to 600 days of age in Nelore cattle. J. Anim. Breed. Genet., 118: 83-92.

Di J, Zhang YYJ, Tian KC, Lazate Liu JF, Xu XM, Zhang TH. 2011. Estimation of (co)variance components and genetic parameters for growth and wool traits of Chinese superfine merino sheep with the use of a multi-trait animal model. Livest. Sci., 138: 278-288.

Dodenhoff J, Van Vleck LD, Gregory KE. 1999. Estimation of direct, maternal, and grandmaternal genetic effects for weaning weight in several breeds of beef cattle. J. Anim. Sci., 77: 840-845.

Eler JP, Ferraz JBS, Golden BL, Pereira E. 2000. Influência da interação touro $\mathrm{x}$ rebanho na estimação da correlação entre efeitos genéticos direto e materno em bovinos da raça Nelore. R. Bras. Zootec., 29: 1642-1648.

Falconer DS, Mackay TFC. 1996. Introduction to Quantitative Genetics (4th ed.). Longman.

Gowane GR, Prince LLL, Lopes FB, Paswan C, Sharma RC. 2015. Genetic and phenotypic parameter estimates of live weight and daily gain traits in Malpura sheep using Bayesian approach. Small. Rumin. Res., 128: 10-18.

Heydarpour M, Schaeffer LR, Yazdi MH. 2008. Influence of population structure on estimates of direct and maternal parameters. J. Anim. Breed. Genet., 125: 89-99.

Jafaroghli M, Rashidi A, Mokhtari MS, Shadparvar AA. 2010. (Co)variance components and genetic parameter estimates for growth traits in Moghani sheep. Small. Rumin. Res., 91: 170-177.

Jalil-Sarghale A, Kholghi M, Shahrebabak Moradi M, Shahrebabak Moradi H, Mohammadi H, Abdollahi-Arpanahi R. 2014. Model comparisons and genetic parameter estimates of growth traits in Baluchi sheep. Slovak J. Anim. Sci., 1: 1218.

Khorsand A, Hafezian SH, Teimouri-Yansari A, Farhadi A. 2014. Genetic Parameters of Direct and Maternal Effects for Growth Traits of Afshari Sheep. Iran. J. Appl. Anim. Sci., 4: 69-74.

Kleiber M. 1947. Body size and metabolic rate. Physiol. Rev., 27(4): 511-541.

Kushwaha BP, Mandal A, Arora AL, Kumar R, Kumar S, Notter DR. 2009. Direct and maternal (co)variance components and heritability estimates for body weights in Chokla sheep. J. Anim. Breed. Genet., 126: 278-287.

Mandal A, Neser FW C, Rout PK, Roy R, Notter DR. 2006. Estimation of direct and maternal (co)variance components for pre-weaning growth traits in Muzaffarnagari sheep. Livest. Sci., 99: 79-89. 
Mandal A, Roy R, Rout PK. 2008. Direct and maternal effects for body measurements at birth and weaning in Muzaffarnagari sheep of India. Small. Rumin. Res., 75: 123-127.

Maniatis N, Pollott GE. 2002. Maternal effects on weight and ultrasonically measured traits of lambs in a small closed Suffolk flock. Small. Rumin. Res., 45: 235-246.

Meyer K. 1992. Variance components due to direct and maternal effects for growth traits of Australian beef cattle. Livest. Prod. Sci.,, 31: 179-204.

Meyer K. 1997. Estimates of genetic parameters for weaning weight of beef cattle accounting for direct-maternal environmental covariances. Livest. Prod. Sci., 52: 187-199.

Mohammadi H, Shahrebabak MM, Shahrebabak HM, Bahrami A, Dorostkar M. 2013. Model comparisons and genetic parameter estimates of growth traits in Baluchi sheep. Arch. Tierz., 56: 12-18.

Mohammadi K, Rashidi A, Mokhtari MS, Nassiri MTB. 2011. The estimation of (co)variance components for growth traits and Kleiber ratios in Zandi sheep. Small. Rumin. Res., 99: 116-121.

Mokhtari MS, Shahrebabak MM, Shahrebabk HM, Sadeghi M. 2013. Estimation of (co) variance components and genetic parameters for growth traits in Arman sheep. J. Livest. Sci. Technol., 1: 35-43.

Mrode RA. 2014. Linear Models for the Prediction of Animal Breeding Values: 3rd Edition. CABI.

Ozcan M, Ekiz B, Yilmaz A, Ceyhan A. 2005. Genetic parameter estimates for lamb growth traits and greasy fleece weight at first shearing in Turkish Merino sheep. Small. Rumin. Res., 56: 215-222.

Rashidi A, Mokhtari MS, Jahanshahi AS, Abadi MRM. 2008. Genetic parameter estimates of pre-weaning growth traits in Kermani sheep. Small. Rumin. Res., 74: 165-171.

Robinson DL. 1996. Estimation and interpretation of direct and maternal genetic parameters for weights of Australian Angus cattle. Livest. Prod. Sci., 45: 1-11.
Roff DA. 2002. Life history evolution. (D. Roff, Ed.), Sinauer Associates, Inc.

Safari E, Fogarty NM, Gilmour AR. 2005. A review of genetic parameter estimates for wool, growth, meat and reproduction traits in sheep. Livest. Prod. Sci., 92: 271-289.

Scholtz MM, Roux CZ. 1988. The Kleiber ratio (growth rate/metabolic mass) as possible selection criteria in the selection of beef cattle. In Proceedings of the 3rd World Congress on Sheep and Beef Cattle Breeding. (pp. 373-375). Paris, France.

Shiotsuki L, de Oliveira DP, Lôbo RNB, Facó O. 2014. Genetic parameters for growth and reproductive traits of Morada Nova sheep kept by smallholder in semi-arid Brazil. Small. Rumin. Res., 120: 204-208.

SPSS. 2008. SPSS Statistics for Windows. Chicago, IL.: SPSS Inc.

Tamioso PR, Alberti Filho JL, Talarico Dias L, de Almeida Teixeira R. 2013. Estimates of (co)variance components and genetic parameters for growth traits in Suffolk lambs. Ciênc. Rural, 43: 2215-2220.

Tosh JJ, Kemp RA. 1994. Estimation of variance components for lamb weights in three sheep populations. J. Anim. Sci., 72: 1184-1190.

Valerio D, Gutiérrez G, Chávez J. 2015. Efectos Genéticos Directo y Materno sobre el Crecimiento de Ovinos de la Raza Junín. Rev. investig. vet. Perú, 26: 28-35.

Vergara OD, Ceron-Muñoz MF, Arboleda EM, Orozco Y, Ossa GA. 2009. Direct genetic, maternal genetic, and heterozygosity effects on weaning weight in a Colombian multibreed beef cattle population. J. Anim. Sci., 87: 516-521.

Willham RL. 1972. The role of maternal effects in animal breeding: III. Biometrical aspects of maternal effects in animals. J. Anim. Sci., 35: 1288-1293.

Zishiri OT, Cloete SWP, Olivier JJ, Dzama K. 2014. Genetic parameters for live weight traits in South African terminal sire sheep breeds. Small. Rumin. Res., 116: 118-125. 